\title{
Mathematical Modeling of Heat Transfer in Counter- Current Fluid Flow in Well-Drilling Systems
}

\author{
Liqun Shan ${ }^{1}$ and Boyun $\mathrm{Guo}^{2 *}$ \\ ${ }^{1}$ Information Center, Dagang Oilfield Company, Dagang, Tianjin 300280, China \\ ${ }^{2}$ P O Box 44690, Lafayette, LA 70504, U.S.A \\ *Corresponding author
}

\begin{abstract}
The performance of gas-drilling (drilling oil and gas wells with air, nitrogen, or natural gas) is very unpredictable in many areas due to lacking of proper design of drilling parameters because of limited understanding of gas-rock interaction which requires knowledge of heat transfer in the well system. Complete analysis of rock failure requires an accurate mathematical model to predict gas temperature at bottom hole. The currently available mathematical models are found not suitable to use for the purpose because they do not consider the effects of formation fluid influx, Joule-Thomason cooling, and entrained drill cuttings. A new analytical solution for predicting gas temperature profiles inside drill strings and in the annulus was derived in this study for gas-drilling, considering all of these three effects. The temperature profiles given by the new analytical solution are found significantly higher than that given by a previous analytical model. Results of sensitivity analyses show that formation fluid influx can significantly increase the temperature profiles in both the drill string and the annulus. The JouleThomason cooling effect lowers the temperature in the annulus only at the bottom hole. The drill cuttings entrained at the bottom hole can slightly increase the temperature profile in the annulus.
\end{abstract}

Keywords-temperature; gas-drilling; prediction; reservoirs; unconventional

\section{INTRODUCTION}

Gas (air, nitrogen, or natural gas) has been widely used as the working fluid in drilling mining boreholes, geothermal fluid wells, and oil and natural gas recovery wells (Lyons et al., 2009). The rate of penetration (ROP) is usually more than 10 times higher in gas-drilling than in liquid-drilling (drilling with water, mud, or oil). However, the performance of gasdrilling is highly inconsistent in many areas. This is generally attributed to rock failure mechanism involving thermal effect (Li et al., 2014).

The primary rock failure mechanism was identified as the mechanical action of drill bit teeth that causes wedging, scraping and grinding, and crushing of rock (Moore,1958). The secondary rock failure mechanism was believed to be the erosion by fluid jet action (Bourgoyne et al., 1986). These mechanisms do not explain why the rate of penetration increases as the bottom hole pressure decreases. A number of technical documents have addressed the effects of confining stress and fluid pressure on rock failure (Murray and Cunningham, 1955; Cunningham and Fenink, 1959; Black and Green, 1978) in liquid-drilling. It has been commonly recognized that reducing bottom hole pressure can significantly increase ROP. This is because the low-level bottom hole pressure causes high-level unbalance of stress in the rock, making the rock softer and easier to break down under the mechanical action of drill bit teeth. The effect of bottom hole pressure on rock failure seems to explain the extremely high rate of penetration in gas-drilling (Sheffield and Sitzman, 1985; Li et al., 2006; Wang et al., 2008).

Zhang et al. (2012) presented their results of analytical and numerical modeling which reveal that gas-cooling to the bottom hole rock is another mechanism of rock failure in gasdrilling. It indicates that a rock layer of about $1.2 \mathrm{~cm}$ thick is under failure condition due to the cooling effect. Li et al.'s (2012a) experimental data demonstrates that this thermal effect drops when gas flow rate increases. This was interpreted as the gas "penetration" effect that pushes the temperature gradient inside the rock body. The mechanism of cooling failure of rock was verified by Zhang et al.'s (2014) experimental work that shows that the cooling effect can increase rate of penetration by $30 \%$. Field observations also support the hypothesis of thermal failure of rock during gasdrilling. It has been found that drill cuttings collected from gas-drilling are much smaller than those from liquid-drilling. A comparison of drill cuttings collected from gas-drilling and liquid-drilling at similar depths in the same region showed a very significant difference (Li et al., 2013a). The drill cuttings collected from gas drilling are dust-like and are at least thousand-times smaller than the drill cuttings from liquiddrilling. The explanation to this fact is still controversial. Some researchers believe it due to the re-grinding of large cuttings at the bottom hole in the gas-drilled wells (Guo and Ghalambor, 2002). However, re-grinding would significantly reduce the rate of penetration, which does not seem to occur in gas-drilling. Another explanation is the theory of cuttingscrashing by drill string and other cuttings during their flowing up the borehole annulus ( $\mathrm{Li}$ et al., 2013a). This is possible owing to pipe vibration when the drill string rotates at high speed. Crashing can occur between drill pipe and borehole wall, turbulent flow of fluids, uneven borehole gauge, doglegs, etc. The significance of the cuttings-crashing has not been thoroughly investigated. Li et al.'s (2013b) work indicates that the energy required to crash cuttings from $6 \mathrm{~mm}$ to $1 \mathrm{~mm}$ is nearly equal to the energy required to transport the cuttings from bottom hole to surface, which is considered to be not realistic. A reasonable explanation is that the cuttings created by the drill bit are much smaller than $6 \mathrm{~mm}$. A portion of the dust-like cuttings are created at the bottom hole due to the frictional heating effect, or thermal failure of rock. This effect is similar to the weathering effect where the temperature at the 
surface of rock alters rapidly, causing the fast failure of rock surface, generating small sands. If this is the case, the cuttings size should depend on the level of frictional heat generated at bit teeth. High level of frictional heat should promote generation of fine cuttings. According to the theory of frictional heat generation (Kulehytsky-Zhihailo and Evtushenko, 1999; Evtushenko and Pauk, 2002), the heat flux is proportional to the contact pressure (stress). The contact pressure between drill bit and rock is higher at deep depth than that at shallow depth in gas-drilling. This is because low weight on bit is used to drill soft rocks at the shallow depth with high-rate of penetration and high weight on bit is used to drill hard rocks at the deep depth to maintain high-rate of penetration. As the weight on bit increases with depth, the contact stress (weight on bit divided by bit tooth contact area) increases, and thus the frictional heat increases. It is therefore expected that the size of drill cuttings decreases with depth. Li et al. (2012b) demonstrate the trend of change of cuttings size with depth. As the well deepens, the proportion of large-size cuttings drops and that of small cuttings increases. This trend of cuttings size change may be explained by three principles: 1 ) rock drillability drops with depth, 2) more cuttings-collision in deep holes, and 3) more thermal failure of rock in frictionheated deep/hard formations. The fact that cuttings are much finer in gas-drilling than in liquid-drilling at the same depth tends to support the principle of thermal failure more than the other two principles. Li et al. (2014) provides a comprehensive analysis of the thermal effect in gas-drilling. They concluded that the thermal failure process is complicated by the interference between the frictional heating and Joule-Thomson cooling to the rock surface. The Joule-Thomson cooling can promote or inhibit the thermal failure of rock at the bottom hole, depending on its degree of influence on the frictional heating. Increasing weight on bit and rotary speed will promote thermal failure of rock, but may damage drill bit due to over-heating. Adding water to the gas stream to protect the drill bit will cool down the rock, reduce the thermal failure of rock, and thus lower the rate of penetration. The thermal failure should be more pronounced in drilling shale gas formations because shale has lower tensile strength than sandstones. Obviously, in order to optimize gas-drilling parameters using the thermal effect, it is very essential to be able to predict the gas temperature at the bottom hole.

A number of researchers have investigated the methods for predicting fluid temperature profiles in drilling circulation systems. Among them are Zhang et al. (2011), Hasan and Kabir (2012), are Kutasov and Eppelbaum (2015). Unfortunately, all these methods were developed for liquiddrilling, not for gas-drilling. Two methods are found applicable to gas-drilling. They are the numerical simulator developed by Wang et al. (2007) and the analytical method presented by Li et al. (2015). The former was published in a Chinese journal and the simulator is not accessible to the authors. The latter model treats the annular fluid as a nonflowing layer of insulation and uses equivalent thermal conductivity of the flowing fluid in the annulus. Also it does not consider the effects of formation fluid influx and drill cuttings and it does not predict annular temperature profile. Application of the model requires input data for the equivalent thermal conductivity of the fluid mixture in the annular space. This data is difficult to obtain, if not impossible.

A new analytical solution was derived in this study to improve Li et al.'s (2015) model for temperature prediction, considering the flowing gas, formation fluid influx, JouleThomason cooling, and entrained cuttings in the annular space. It corrects the result given by $\mathrm{Li}$ et al.'s (2015) model by $14 \%$.

\section{MATHEMATICAL MODEL}

The temperature profiles inside drill string and in the annular space are mainly controlled by the following six factors:

- Gas injection rate that brings heat to the inside of drill string;

- $\quad$ Lateral heat transfer through drill string;

- Joule-Thomason cooling effect at bit orifices;

- Heat brought to the bottom hole by drill cuttings;

- Heat brought to the bottom annulus by the formation fluid influx; and

- Lateral heat transfer through casing and cement sheath.

The friction pressure loss also generates heat in the system. In the practical ranges of pressure (5 to $15 \mathrm{MPa}$ ) and temperature (0 to $100 \mathrm{oC})$, gas density varies from 1 to 100 $\mathrm{kg} / \mathrm{m} 3$ and its viscosity changes from $13.3 \times 10-6 \mathrm{~m} 2 / \mathrm{s}$ to 22.1x10-6 m2/s (Kadoya et al., 1985). For this dilute gas, the friction pressure loss is less than $5 \mathrm{MPa}$ in the typical gasdrilling systems. Therefore the heat generation due to friction is negligible.

The thermal conductivities of steel drill string and gas at $50 \mathrm{oC}$ are $43 \mathrm{~W} / \mathrm{m}$ - oC and $0.0127 \mathrm{~W} / \mathrm{m}$-oC, respectively. The high contrast ( $>1500$ times) in thermal conductivity makes the fluid in the annulus the dominating material (limiting step) for the heat conduction in the radial direction. Therefore, the resistance to heat conduction in drill string is negligible. The thermal conductivity of gas can be used to calculate heat flow across the drill string. The thermal conductivities of steel casing and cement concrete at 50oC are $43 \mathrm{~W} / \mathrm{m}-\mathrm{oC}$ and 1.7 $\mathrm{W} / \mathrm{m}-\mathrm{oC}$, respectively. The high contrast ( $>25$ times) in thermal conductivity makes the cement sheath the dominating material (limiting step) for the heat conduction in the radial direction. Therefore, the resistance to heat conduction in casing is negligible.

When gas is injected into a drill string, the heat brought to the inside of string is proportional to the product of fluid heat capacity $C_{p}$ and mass flow rate $\dot{m}_{p}$ where

$$
\dot{m}_{p}=\rho_{p} Q_{p}
$$

where $\rho_{p}$ and $Q_{p}$ are gas density and volumetric flow rate inside drill string. As the gas flows down the drill string, the rate of heat transfer through drill string is proportional to the 
thermal conductivity of string $K_{p}$. When the drilling fluid expands below the bit orifices, its temperature drops due to Joule-Thomason cooling effect. The downstream temperature can be expressed as (Guo and Liu, 2011):

$$
T_{d n}=T_{u p}\left(\frac{P_{d n}}{P_{u p}}\right)^{\frac{k-1}{k}}
$$

where $T_{d n}$ and $T_{u p}$ are the absolute temperatures in the downstream and upstream of bit orifices, respectively, $P_{d n}$ and $P_{u p}$ are the absolute pressures in the downstream and upstream of bit orifices, respectively, and $\mathrm{k}$ is the specific heat ratio of gas ( $\mathrm{k}=1.3$ for gas). The temperature drop at the bit is expressed as:

$$
\Delta T_{J}=T_{u p}-T_{d n}
$$

The gas receives heat from the entrained drill cuttings and formation oil influx. Assuming all formation fluid influx occurs at bottom hole, the fluid temperature should change at bottom hole in the annulus by

$$
\Delta T_{b}=-\Delta T_{J}+\Delta T_{c}+\Delta T_{f}
$$

where $\quad \mathrm{c}$ and $\mathrm{f}$ are temperature changes due to added drill cutting and fluid influx, respectively. It can be shown that in the practical drilling conditions where the rate of penetration is less than $50 \mathrm{~m} /$ hour, the term $\quad \mathrm{c}$ is negligible. The annular temperature at the bottom hole Tbh can be expressed as:

$$
T_{b h}=\frac{C_{p} \dot{m}_{p}\left(T_{p}-\Delta T_{J}\right)+C_{f} \dot{m}_{f} T_{\max }}{C_{p} \dot{m}_{p}+C_{f} \dot{m}_{f}}
$$

where $T_{p}$ is the temperature of fluid inside the drill string, $C_{f}$ is the heat capacity of the fluid influx, $\dot{m}_{f}$ is the mass flow rate of fluid influx, and $T_{\max }$ is the geo-temperature at the bottom hole depth. Therefore the temperature change at the bottom hole can be expressed as:

$$
\Delta T_{b}=T_{b h}-T_{p}=\frac{C_{p} \dot{m}_{p}\left(T_{p}-\Delta T_{J}\right)+C_{f} \dot{m}_{f} T_{\max }}{C_{p} \dot{m}_{p}+C_{f} \dot{m}_{f}}-T_{p}
$$

The heat transfer in the annulus depends on the product of mixture heat capacity $C_{a}$ and mixture mass flow rate $\dot{m}_{a}$ where

$$
C_{a} \dot{m}_{a}=C_{p} \dot{m}_{p}+C_{s} \dot{m}_{s}+C_{f} \dot{m}_{f}
$$

where the product of heat capacity and mass flow rate of solid cuttings $C_{s} \dot{m}_{s}$ is further expressed in two terms:

$$
C_{s} \dot{m}_{s}=C_{h} \dot{m}_{h}+C_{r} \dot{m}_{r}
$$

where $C_{h}$ and $C_{r}$ are the heat capacities of hydrocarbon and dry rock in the cuttings, respectively. The mass flow rates of the hydrocarbon and rock in the cuttings are respectively expressed as:

$$
\dot{m}_{h}=\frac{\pi}{4} D_{b}^{2} R_{P} \varphi \rho_{h}
$$

and

$$
\dot{m}_{r}=\frac{\pi}{4} D_{b}^{2} R_{P}(1-\varphi) \rho_{r}
$$

where $\mathrm{Db}, \mathrm{RP}, \quad$, $\mathrm{h}$, and $\mathrm{r}$ are drill bit diameter, rate of penetration, rock porosity, density of hydrocarbon, and density of rock, respectively. The Cf in (4) is heat capacity of formation influx fluid (usually oil) and mass flow rate of formation fluid influx is expressed as

$$
\dot{m}_{f}=\rho_{f} Q_{f}
$$

where $\mathrm{f}$ and Qf are density of fluid influx and flow rate of fluid influx, respectively. As the fluid mixture flows up the annulus, the rates of heat transfer through drill string and cement sheath are proportional to the thermal conductivities of drill string $K_{p}$ and cement sheath $K_{c}$, respectively (the thermal conductivity of casing is assumed to be infinity compared to that of cement sheath).

The gas temperatures inside the drill string $\mathrm{Tp}$ and in the annulus Ta take the following forms respectively (derivation of solution is given in Appendix):

$$
T_{p}=C_{1} A e^{r_{1} L}+C_{2} A e^{r_{2} L}+G L+\frac{A G+A B T_{g 0}-G(B+E)}{A B}
$$

and

$$
T_{a}=C_{1}\left(A+r_{1}\right) e^{r_{1} L}+C_{2}\left(A+r_{2}\right) e^{r_{2} L}+G L+\frac{A G+A B T_{g 0}-E G}{A B}
$$

where

$$
C_{1}=\frac{A B\left(A \Delta T_{b}-G\right)-\left[A B T_{p 0}-A B T_{g 0}-A G+G(B+E)\right] r_{2} e^{r_{2} L_{\max }}}{A^{2} B\left(r_{1} e^{r_{1} L_{\max }}-r_{2} e^{r_{2} L_{\max }}\right)}
$$




$$
\begin{aligned}
& C_{2}=\frac{-A B\left(A \Delta T_{b}-G\right)+\left[A B T_{p 0}-A B T_{g 0}-A G+\right.}{A^{2} B\left(r_{1} r^{r_{1} L_{\max }}-r_{2} e^{r_{2} L_{\max }}\right)} \\
& r_{1}=\frac{B+E-A+\sqrt{(B+E-A)^{2}+4 A B}}{2} \\
& r_{2}=\frac{B+E-A-\sqrt{(B+E-A)^{2}+4 A B}}{2}
\end{aligned}
$$

where

$$
\begin{gathered}
A=\frac{\pi d_{p} K_{p}}{C_{p} \dot{m}_{p} t_{p}} \\
B=\frac{\pi d_{c} K_{c}}{C_{a} \dot{m}_{a} t_{c}} \\
E=\frac{\pi d_{p} K_{p}}{C_{a} \dot{m}_{a} t_{p}}
\end{gathered}
$$

where all symbols are defined in the Nomenclature section.

Because (6) involves the in-string temperature $\mathrm{Tp}$ at bottom depth, it is necessary to solve (6) and (12) simultaneously with a numerical method such as NewtonRaphson iteration. These equations were solved in a spreadsheet program using the Goal Seek tool in MS Excel.

\section{MODEL COMPARISON}

The newly derived analytical solution was coded in an MS Excel spreadsheet to compare with other models. A number of numerical models have been presented for fluid temperature prediction, including Keller et al. (1973), Wooley (1980) , Marshall and Bentsen (1982), Kabir at al. (1996) and Hasan and Kabir (2012). Unfortunately all these models were developed for liquid or multi-phase flow. They are not applicable to gas flow in gas-drilling. The analytical model for gas-drilling presented by $\mathrm{Li}$ et al. (2015) was used for comparison. The data used in the models are provided in Table 1.

Gas is the major component of air (>78\%). Heat capacity of gas is a function of temperature and pressure (Abbott and van Ness, 1989). In the temperature range between 0oC and $100 \mathrm{oC}$ at atmospheric pressure, the heat capacity of air varies between $1,005 \mathrm{~J} / \mathrm{kg}-\mathrm{C}$ and $1,009 \mathrm{~J} / \mathrm{kg}-\mathrm{C}$, or within $0.40 \%$. In gas-drilling operations the gas pressure in the drill string is in a narrow range between $7 \mathrm{MPa}$ and $10 \mathrm{MPa}$. The heat capacity of gas varies between $1,016.2 \mathrm{~J} / \mathrm{kg}-\mathrm{C}$ and $1,021.6 \mathrm{~J} / \mathrm{kg}-\mathrm{C}$, or within $0.53 \%$, in this pressure range (Kadoya et al., 1985). Considering the extreme condition of $0 \mathrm{oC}$ and $10 \mathrm{MPa}$, the heat capacity of gas varies between $1,005 \mathrm{~J} / \mathrm{kg}-\mathrm{C}$ and 1,021.6

\begin{tabular}{|c|c|c|}
\hline Factor & Value & Unit \\
\hline Depth (L) & 2000 & $\mathrm{~m}$ \\
\hline Bit diameter $\left(D_{b}\right)$ & 0.201 & $\mathrm{~m}$ \\
\hline Inner diameter of cement $\left(\mathrm{d}_{\mathrm{c}}\right)$ & 0.245 & $\mathrm{~m}$ \\
\hline Outer diameter of cement $\left(D_{c}\right)$ & 0.311 & $\mathrm{~m}$ \\
\hline Outer diameter of drill string $\left(D_{p}\right)$ & 0.114 & $\mathrm{~m}$ \\
\hline Inner diameter of drill string $\left(d_{p}\right)$ & 0.098 & $\mathrm{~m}$ \\
\hline Geothermal temp at surface $\left(\mathrm{T}_{\mathrm{g} 0}\right)$ & 20 & ${ }^{\circ} \mathrm{C}$ \\
\hline Geothermal gradient $(G)$ & 0.0245 & $\mathrm{C} / \mathrm{m}$ \\
\hline Thermal conductivity of cement $\left(\mathrm{K}_{\mathrm{c}}\right)$ & 1.7 & $\mathrm{~W} / \mathrm{m}-{ }^{\circ} \mathrm{C}$ \\
\hline Thermal conductivity of annulus $\left(K_{p}\right)$ & 0.0271 & $\mathrm{~W} / \mathrm{m}-{ }^{\circ} \mathrm{C}$ \\
\hline Injection rate $\left(Q_{p}\right)$ & 1.08 & $\mathrm{~m}^{3} / \mathrm{s}$ \\
\hline Temperature of injected fluid $\left(T_{p 0}\right)$ & 40 & ${ }^{\circ} \mathrm{C}$ \\
\hline Heat capacity of fluid inside pipe $\left(C_{p}\right)$ & 1005 & $\mathrm{~J} / \mathrm{kg}-{ }^{\circ} \mathrm{C}$ \\
\hline Heat capacity of rock $\left(C_{r}\right)$ & 920 & $\mathrm{~J} / \mathrm{kg}-{ }^{\circ} \mathrm{C}$ \\
\hline Heat capacity of formation fluid $\left(C_{f}\right)$ & 1880 & $\mathrm{~J} / \mathrm{kg}-{ }^{\circ} \mathrm{C}$ \\
\hline Porosity ( ) & 0.3 & \\
\hline Rate of penetration $\left(R_{p}\right)$ & 0 & $\mathrm{~m} / \mathrm{h}$ \\
\hline Temperature drop at bit ( $\mathrm{Tb}$ ) & 0 & ${ }^{\circ} \mathrm{C}$ \\
\hline Density of rock $(r \quad)$ & 2650 & $\mathrm{~kg} / \mathrm{m}^{3}$ \\
\hline Density of formation fluid $(f \quad)$ & 1000 & $\mathrm{~kg} / \mathrm{m}^{3}$ \\
\hline Density of injected fluid $(p)$ & 1.127 & $\mathrm{~kg} / \mathrm{m}^{3}$ \\
\hline Formation fluid influx rate $\left(Q_{f}\right)$ & 0 & $\mathrm{~m}^{3} / \mathrm{s}$ \\
\hline
\end{tabular}
$\mathrm{J} / \mathrm{kg}-\mathrm{C}$, or within $1.65 \%$. Therefore, the heat capacity of gas was assumed to be constant in this study.
TABLE I. DATA USED IN COMPARISON OF ANALYTICAL SOLUTIONS

Figure 1 indicates that the injected gas is cooled down in the upper section of drill string by the geothermal gradient. Gas is then heated up by the geothermal gradient in the lower section of drill string. After arrival in the annulus, the gas is quickly heated up by the geothermal gradient in the lower section of the annulus. Eventually the gas is cooled down in the upper section of the annulus by the geothermal gradient.

Also presented in Figure 1 is the gas temperature profile inside the drill string given by Li et al.'s (2015) analytical model. It is seen that the bottom hole temperature given by the new analytical model is 7oC higher than that given by $\mathrm{Li}$ et al.'s (2015) model. If the new model is considered to be accurate, Li et al.'s (2015) model is expected to underestimate bottom hole temperature by $14 \%$. 


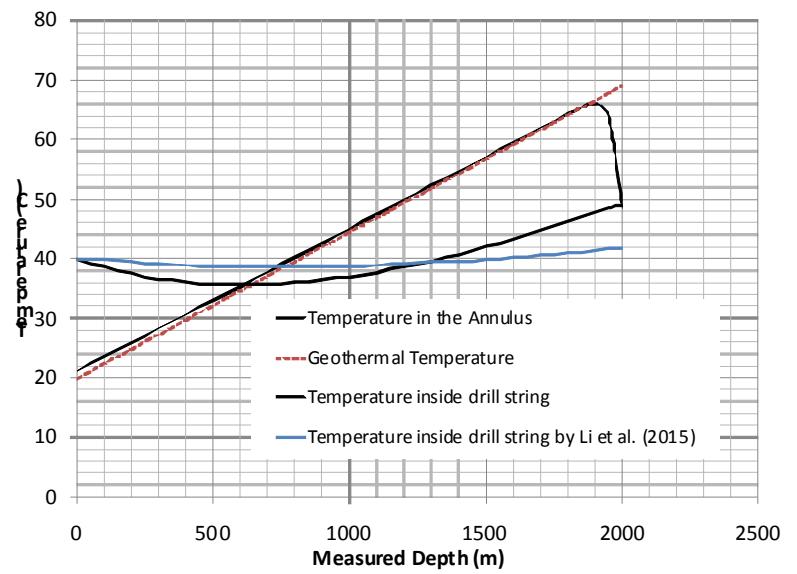

FIGURE I. A COMPARISON OF TEMPERATURE PROFILES GIVEN BY DIFFERENT ANALYTICAL MODELS

\section{SENSITIVITY ANALYSIS}

Previous models do not consider the effects of formation fluid influx, Joule-Thomason cooling, and entrained drill cuttings at bottom hole on the temperature profiles inside drill string and in the annulus. These effects were analyzed with the new model in this study. Figure 2 demonstrates the effect of formation fluid influx on the temperature profiles. It shows that the formation fluid influx can significantly increase the temperature profiles in both the drill string and the annulus. Figure 3 illustrates the effect of Joule-Thomason cooling on the temperature profiles. It is seen that the Joule-Thomason cooling effect lowers the temperature in the annulus only at the bottom hole. It diminishes quickly in a very short interval when the drilling fluid moves up the annulus. Figure 4 shows the effect of entrained drill cuttings on the temperature profiles. It indicates that the drill cuttings can slightly increase the temperature profile in the annulus even at very high rate of penetration up to $60 \mathrm{~m} /$ hour.

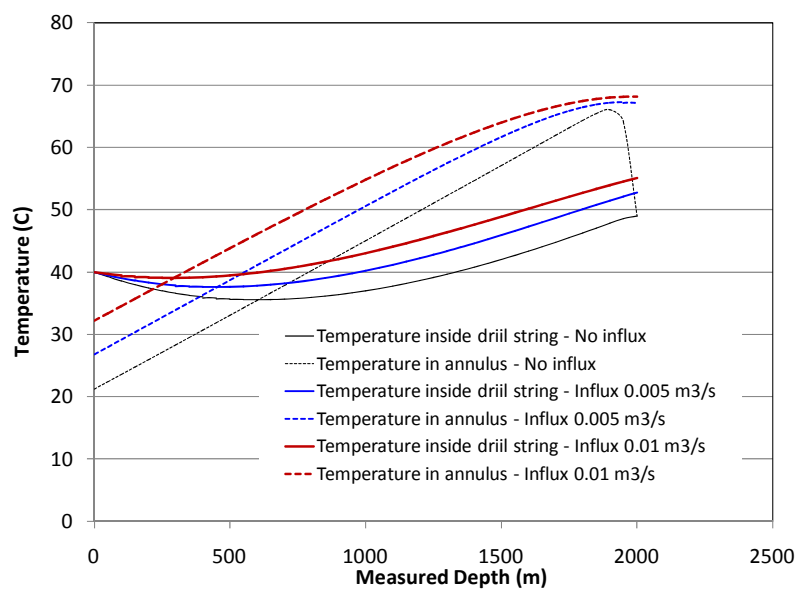

FIGURE II. EFFECT OF FORMATION FLUID INFLUX ON THE TEMPERATURE PROFILES

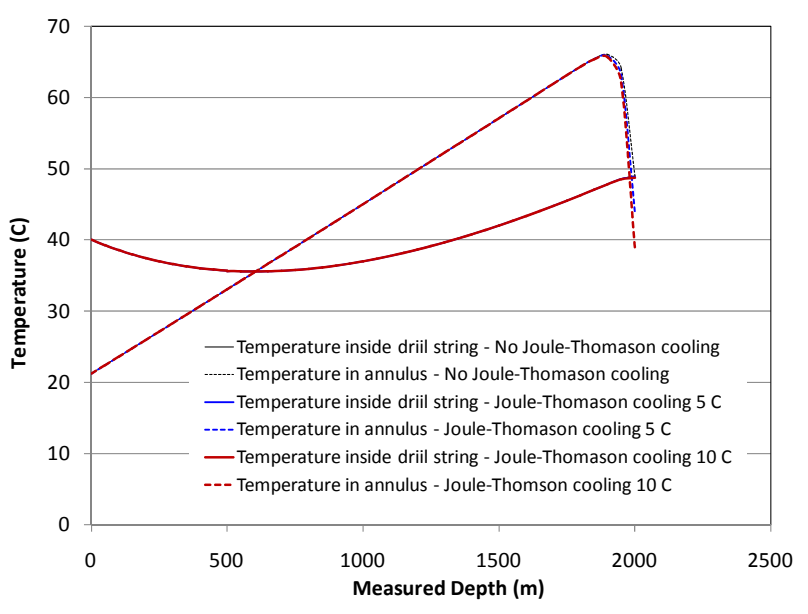

FIGURE III. EFFECT OF JOULE-THOMASON COOLING ON THE TEMPERATURE PROFILES

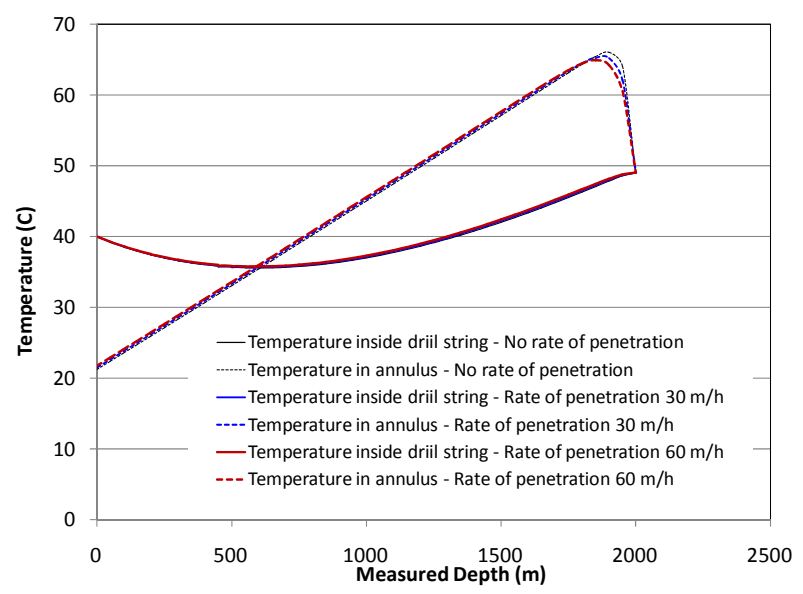

FIGURE IV. EFFECT OF ENTRAINED DRILL CUTTINGS ON THE TEMPERATURE PROFILES

\section{CONCLUSIONS}

The following conclusions are drawn from this study:

A new closed form analytical solution for predicting gas temperature profiles inside drill strings and in the annulus was derived in this study for gas-drilling. The new solution has advantages over existing solution in that it can handle formation fluid influx, Joule-Thomason cooling effect, and entrained drill cuttings.

An example calculation shows that the injected hot gas is cooled down in the upper section of drill string by the geothermal gradient. Gas is then heated up by the geothermal gradient in the lower section of drill string. After arrival in the annulus, the gas is quickly heated up by the geothermal gradient in the lower section of the annulus. Eventually the gas is cooled down in the upper section of the annulus by the geothermal gradient.

The temperature profiles given by the new analytical solution are significantly different from that given by $\mathrm{Li}$ et 
al.'s analytical model. If the new model is considered to be accurate, Li et al.'s (2015) model is expected to underestimates bottom hole temperature by $14 \%$.

Results of sensitivity analyses show that formation fluid influx can significantly increase the temperature profiles in both the drill string and the annulus. The Joule-Thomason cooling effect lowers the temperature in the annulus only at the bottom hole. The drill cuttings entrained at the bottom hole can slightly increase the temperature profile in the annulus.

The new analytical solution has some limitations including steady gas flow. Also it may give erroneous result if the equivalent thermal conductivity of annular fluid is not correctly estimated. Thermal conductivity values should be adjusted based on temperature measurements in critical applications.

Direct measurement of temperature profiles are required to further validate the new analytical solution. Once validated the new solution can replace numerical simulators that are not readily available to field engineers in general.

\section{ACKNOWLEDGMENT}

This research was supported by the China National Natural Science Foundation Founding No. 51134004.

\section{NOMENCLATURE}

Aa $=$ cross-sectional area of annulus (m2)

Ap = cross-sectional area of drill pipe $(\mathrm{m} 2)$

$\mathrm{Ca}=$ heat capacity of fluid in the annulus (J/kg-oC)

Cf = heat capacity of formation fluid influx (J/kg-oC)

Ch = heat capacity of hydrocarbons in cuttings (J/kg-oC)

$\mathrm{Cp}=$ heat capacity of fluid inside drill pipe (J/kg-oC)

$\mathrm{Cr}$ = heat capacity of rock $(\mathrm{J} / \mathrm{kg}-\mathrm{oC})$

Cs = heat capacity of solid in the annulus ( $/ \mathrm{kg}-\mathrm{oC})$

$\mathrm{Db}=$ bit-diameter $(\mathrm{m})$

dc = inner-diameter of cement sheath (m)

Dc = outer-diameter of cement sheath (m)

dp = inner-diameter of drill pipe (m)

Dp = outer-diameter of drill pipe (m)

$\mathrm{G}=$ geothermal gradient $(\mathrm{oC} / \mathrm{m})$

$\mathrm{k} \quad=$ specific heat ratio of gas (dimensionless)

$\mathrm{Kc}=$ thermal conductivity of cement $(\mathrm{W} / \mathrm{m}-\mathrm{oC})$

$\mathrm{Kp}=$ thermal conductivity of drill pipe (W/m- oC)

$\mathrm{L} \quad=$ wellbore depth along the drill string (m)

Lmax = the maximum hole depth (m)

$\dot{m}_{a} \quad=$ mass flow rate in the annulus $(\mathrm{kg} / \mathrm{s})$ $\dot{m}_{f}=$ mass flow rate of formation fluid influx $(\mathrm{kg} / \mathrm{s})$

$\dot{m}_{h}=$ mass flow rate of hydrocarbons in cuttings $(\mathrm{kg} / \mathrm{s})$

$\dot{m}_{p} \quad=$ mass flow rate inside the drill pipe $(\mathrm{kg} / \mathrm{s})$

$\dot{m}_{s}=$ mass flow rate of solid cuttings in the annulus $(\mathrm{kg} / \mathrm{s})$

$\dot{m}_{r} \quad=$ mass flow rate of rock $(\mathrm{kg} / \mathrm{s})$

Pdown = absolute pressure in the downstream (psi)

Pup = absolute pressure in the upstream (psi)

$Q_{f} \quad=$ formation fluid influx rate $(\mathrm{m} 3 / \mathrm{s})$

$Q_{p} \quad=$ fluid injection flow rate $(\mathrm{m} 3 / \mathrm{s})$

$\mathrm{RP}=$ rate of penetration $(\mathrm{m} / \mathrm{s})$

tc = thickness of cement sheath (m)

tp = wall thickness of drill pipe (m)

$\mathrm{Ta}=$ temperature of annular fluid (oC)

$\mathrm{Tb}=$ temperature change at drill bit (oC)

Tdn = absolute temperature in the downstream (oC)

$\mathrm{Tg}$ = geothermal temperature at depth (oC)

$\operatorname{Tg} 0$ = geothermal temperature at surface (oC)

$\mathrm{Tp}=$ temperature of fluid inside drill pipe at depth (oC)

$\mathrm{Tp} 0$ = temperature of fluid inside drill pipe at surface (oC)

Tup = absolute temperature in the upstream (oC)

Greeks

$=$ porosity of rock (dimensionless)

$\mathrm{a}=$ fluid mixture density in the annulus $(\mathrm{kg} / \mathrm{m} 3)$

$\mathrm{f}$ = density of formation fluid $(\mathrm{kg} / \mathrm{m} 3)$

$\mathrm{h}=$ density of hydrocarbons in cuttings $(\mathrm{kg} / \mathrm{m} 3)$

$\mathrm{p} \quad$ = fluid density inside drill pipe $(\mathrm{kg} / \mathrm{m} 3)$

$\mathrm{r}$ = density of dry rock $(\mathrm{kg} / \mathrm{m} 3)$

$\mathrm{s} \quad=$ solid density in the annulus $(\mathrm{kg} / \mathrm{m} 3)$

\section{REFERENCES}

[1] Abbott, M.M. and van Ness, H.C., Thermodynamics, 2nd edition, McGraw-Hill Publihsing Company, New York. 1989, pp. 100-101.

[2] Black, A.D., and Green, S.J., Laboratory Simulation of Deep Well Drilling. Petroleum Engineer, March 1978.

[3] Bourgoyne, A.T., Millheim, K.K., Chenevert, M.E., and Young Jr., F.S. Applied Drilling Engineering. Society of Petroleum Engineering, Richardson, TX, 1986, pp. 200-209.

[4] Cunningham, R.A., and Fenink, J.G., "Laboratory Study of Effect of Overburden, Formation, and Mud Column Pressure on Drilling Rate of Permeable Formations,” Trans., AIME 216, 1959, pp. 9-17.

[5] Evtushenko, O.O. and Pauk, V.I., "Steady-State Frictional Heat Generation on a Periodic Sliding Contact,” Journal of Mathematical Sciences, Vol. 109, No. 1, 2002. 
[6] Guo, B. and Ghalambor, A., Natural Gas Engineering Handbook, 2nd Edition, Gulf Publishing Company, Houston , 2012.

[7] Guo, B. and Liu, G., Applied Drilling Circulation Systems. Oxford: Elsevier. 145-150, 2011.

[8] Hasan, A.R. and Kabir, C.S., "Wellbore heat-transfer modeling and applications," Journal of Petroleum Science and Engineering 8687 ,2012, pp. 127-136.

[9] Kabir, C.S., Hasan, A.R., Kouba, G.E., and Ameen, N.M., "Determining circulating fluid temperature in drilling, workover, and well-control operations,” SPE Drilling \& Completion, June 1996, pp. 74-79.

[10] Kadoya, K., Matsunaga, N., and Nagashima, A., "Viscosity and Thermal Conductivity of Dry Air in the Gasous Phase," J. Phys. Chem. Ref. Data, Vol. 14, No. 4, 947-970, 1985.

[11] Keller, H.H., Couch, E.J., and Berry, P.M. “Temperature Distribution in Circulating Mud Columns,” SPE Journal, Vol. 13, No. 1, 23-30, 1973.

[12] Kutasov, I.M. and Eppelbaum, L.V. "Wellbore and Formation Temperatures During Drilling, Cementing of Casing and Shut-in," Proceedings of the World Geothermal Congress 2015 held in Melbourne, Australia, 19-25 April 2015.

[13] Kulchytsky-Zhihailo, R.D. and Evtushenko, A.A. "Steady-State Frictional Heat Generation on Axisymmetric Sliding Contact of a Thermosensitive Sphere and a Fixed, Thermally Insulated Base,” Journal of Applied Mechanics and Technical Physics, Vol. 40, No. 1. 1999.

[14] Li, J., Guo, B., and Ai, C. 2012a. "Analytical and Experimental Investigations of the Effect of Temperature Gradient on Rock Failure," paper IMECE2012-86436 presented at the ASME 2012 International Mechanical Engineering Congress \& Exposition held in Houston, Texas, November 9-15, 2012.

[15] Li, J., Guo, B., Yang, S., and Liu, G. "The Complexity of Thermal Effect on Rock Failure in Gas-Drilling Shale Gas Wells,” Journal of Natural Gas Science and Engineering, Vol. 21, Sept 2014, pp. 255-259.

[16] Li, J., Guo, B., Liu, G., and Liu, W. 2013b. "The Optimum Range of Gas Injection Rate in Shale Gas Well Drilling,” SPE Drilling \& Completion, March 2013, Vol. 28, No. 1.

[17] Li, J., Guo, B., and Li, B., "A closed form mathematical model for predicting gas temperature in gas-drilling unconventional tight reservoirs," Journal of Natural Gas Science and Engineering, 27, 284289, 2015.

[18] Li, Y., Meng, Y., She, Z., and Zhang, J. 2006. "Investigations of Increased Rate of Penetration in Air Drilling,” China Petroleum Drilling and Exploration Technology, 34 (4), 9-11.

[19] Li, J., Yang, S., Guo, B., Feng, Y., and Liu, G. 2012b. "Distribution of the Sizes of Rock Cuttings in Gas Drilling at Various Depths,” Tech Science Press CMES, Vol. 89, No. 2, 79-96.

[20] Li, J., Yang, S. and Liu, G. 2013a. “Cutting Breakage and Transportation Mechanism of Air Drilling,” Int. J. Oil, Gas and Coal Technology, Vol. 6, No. 3, 259-270.

[21] Lyons, W.C., Guo, B., Graham, R.L., and Hawley, G.D., Air and Gas Drilling Manual, 3rd Edition, Elsevier Publishing Company, Amsterdam, 293-308, 2009.

[22] Marshall, D.W. and Bentsen, R.G. 1982. "A Computer Model to Determine the Temperature Distributions in a Wellbore," Journal of Canadian Technology, Jan-Feb. 1982, pp. 63-75.

[23] Moore P. L., "Five Factor that Affect Drilling Rate,” Oil and Gas Jour., Vol.56, No.40, 141-162, 1958.

[24] Murray, A.S. and Cunningham, R.A. "Effect of Mud Column Pressure on Drilling Rate,” Trans., AIME 205, 196-204, 1955.

[25] Sheffield, J.S, Sitzman, J.J. “Air Drilling Practices in the Midcontinent and Rocky Mountain Areas," Paper SPE 13490 Presented at the SPE/IADC Drilling Conference Held in New Orleans, Louisiana, 5-8 March 1985, 575-587.

[26] Wang, Y., Meng, Y., Li, G., Li, Y., Liu, H., Zhang, W., and Chen, Y. "Research on the Influence of Gas Drilling on Penetration Rate," J. of Drilling \& Production Technology (in Chinese), 2008, 31(2), 20-23.

[27] Wang, C., Meng, Y., Jiang, W. "Variation in Wellbore Temperature and Its Effects on Gas Injection Rate," Natural Gas Industry Press (in Chinese), 27(10): 67-69, 2007.
[28] Wooley, G.R. Computing Downhole Temperatures in Circulation, Injection, and Production Wells,” JPT, Sept. 1980, 1509-1522.

[29] Zhang, H., Gao, D., Salehi, S., and Guo, B. "Effect of Fluid Temperature on Rock Failure in Borehole Drilling,” ASCE Journal of Engineering Mechanics, Vol. 140, No. 1, 82-90, 2014.

[30] Zhang, H, Zhang, H., Guo, B., and Gang, M. “Analytical and Numerical Modeling Reveals the Mechanism of Rock Failure in Gas UBD,” Journal of Natural Gas Science and Engineering, January 2012, Vol. 4, 29-34.

[31] Zhang, Y., Pan, L., Pruess, K., and Finsterle, S. “A Time-convolution Approach for Modeling Heat Exchange between a Wellbore and Surrounding Formation,” Geothermics, 40 (2011), 261-266.

\section{Appendix A: MATHEMATICAL Modeling of HeAt TRANSFER IN GAS-DRILLING}

\section{A. Assumptions}

The following assumptions are made in model formulation:

a. The thermal conductivities of casing are assumed to be infinitive.

b. The geothermal gradient behind the annulus is not affected by borehole fluid.

c. Heat capacity of fluid is constant.

d. Friction-induced heat is negligible.

\section{B. Governing Equation}

Figure A.1 depicts a small element of a borehole section with a drill string at center.

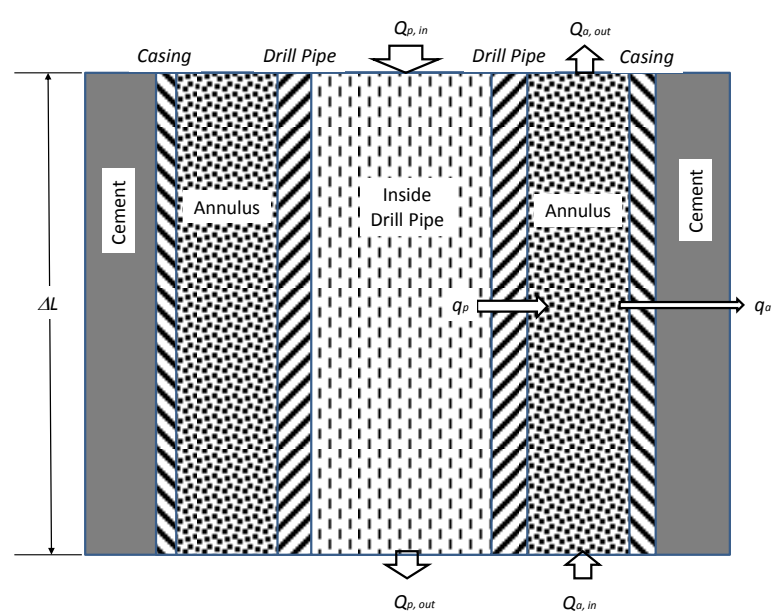

FIGURE A.1. SKETCH ILLUSTRATING HEAT TRANSFER IN A BOREHOLE SECTION

Consider the heat flow inside the drill pipe during a time period of t. Heat balance is given by

$$
Q_{p, \text { in }}-Q_{p, \text { out }}-q_{p}=Q_{p, \text { chng }}
$$

where

Qp,in = heat energy brought into the drill pipe element by fluid due to convection, J Qp,out = heat energy carried away the drill pipe element by fluid due to convection, Jqp = heat transfer through the drill pipe due to conduction, J 
Qp,chng = change of heat energy in the fluid, J.

These terms can be further formulated as

$$
\begin{gathered}
Q_{p, \text { in }}=C_{p} \dot{m}_{p} T_{p, L} \Delta t \\
Q_{p, \text { out }}=C_{p} \dot{m}_{p} T_{p, L+\Delta L} \Delta t \\
q_{p}=\pi d_{p} K_{p} \Delta L\left(-\frac{\partial T_{p}}{\partial r}\right) \Delta t \\
Q_{p, \text { chng }}=C_{p} \rho_{p} A_{p} \Delta L \Delta T_{p}
\end{gathered}
$$

Substituting (A.2) through (A.5) into (A.1) gives

$C_{p} \dot{m}_{p} \Delta t\left(T_{p, L}-T_{p, L+\Delta L}\right)+\pi d_{p} K_{p} \Delta L\left(\frac{\partial T_{p}}{\partial r}\right) \Delta t=\rho_{p} C_{p} A_{p} \Delta L \Delta T_{p}$

Dividing all the terms of this equation by $\mathrm{L}$ t yields

$$
C_{p} \dot{m}_{p} \frac{\left(T_{p, L}-T_{p, L+\Delta L}\right)}{\Delta L}+\pi d_{p} K_{p} \frac{\partial T_{p}}{\partial r}=\rho_{p} C_{p} A_{p} \frac{\Delta T_{p}}{\Delta t}
$$

For infinitesimal of $\mathrm{L}$ and $\mathrm{t}$, this equation becomes

$$
\frac{\partial T_{p}}{\partial L}+\frac{\rho_{p} A_{p}}{\dot{m}_{p}} \frac{\partial T_{p}}{\partial t}=\frac{\pi d_{p} K_{p}}{C_{p} \dot{m}_{p}} \frac{\partial T_{p}}{\partial r}
$$

The radial-temperature gradient in the insulation layer can be formulated as

$$
\frac{\partial T_{p}}{\partial r}=\frac{T_{a}-T_{p}}{t_{p}}
$$

Substituting Eq. (A.9) into Eq. (A.8) yields

$$
\frac{\partial T_{p}}{\partial L}+\lambda_{p} \frac{\partial T_{p}}{\partial t}+\alpha_{p}\left(T_{p}-T_{a}\right)=0
$$

where

$$
\begin{gathered}
\lambda_{p}=\frac{\rho_{p} A_{p}}{\dot{m}_{p}} \\
\alpha_{p}=\frac{\pi d_{p} K_{p}}{C_{p} \dot{m}_{p} t_{p}}
\end{gathered}
$$

Consider the heat flow in the annulus during a time period of $t$. Heat balance is given by

$$
Q_{a, \text { in }}-Q_{a, \text { out }}+q_{p}-q_{a}=Q_{a, \text { chng }}
$$

where

Qa,in = heat energy brought into the drill pipe element by fluid due to convection, J Qa,out = heat energy carried away the drill pipe element by fluid due to convection, $\mathrm{J}$ qa = heat transfer through casing and cement due to conduction, J Qa,chng= change of heat energy in the fluid, J. These terms can be further formulated as

$$
\begin{gathered}
Q_{a, \text { in }}=C_{a} \dot{m}_{a} T_{a, L+\Delta L} \Delta t \\
Q_{a, \text { out }}=C_{a} \dot{m}_{a} T_{a, L} \Delta t \\
q_{a}=\pi d_{c} K_{c} \Delta L\left(-\frac{\partial T_{a}}{\partial r}\right) \Delta t \\
Q_{a, \text { chng }}=C_{a} \rho_{a} A_{a} \Delta L \Delta T_{a}
\end{gathered}
$$

Substituting (A.15) through (A.18) into (A.14) gives
$C_{a} \dot{m}_{a} \Delta t\left(T_{a, L+\Delta L}-T_{a, L}\right)-\pi d_{p} K_{p} \Delta L\left(\frac{\partial T_{p}}{\partial r}\right) \Delta t+\pi d_{c} K_{c} \Delta L\left(\frac{\partial T_{a}}{\partial r}\right) \Delta t=\rho_{a} C_{a} A_{a} \Delta L \Delta T_{a}$

Dividing all the terms of this equation by $\mathrm{L}$ t yields $C_{a} \dot{m}_{a} \frac{\left(T_{a, L+\Delta L}-T_{a, L}\right)}{\Delta L}-\pi d_{p} K_{p}\left(\frac{\partial T_{p}}{\partial r}\right)+\pi d_{c} K_{c}\left(\frac{\partial T_{a}}{\partial r}\right)=\rho_{a} C_{a} A_{a} \frac{\Delta T_{a}}{\Delta t}$ (A.20)

For infinitesimal of $L$ and $t$, this equation becomes $C_{a} \dot{m}_{a} \frac{\partial T_{a}}{\partial L}-\rho_{a} C_{a} A_{a} \frac{\partial T_{a}}{\partial t}-\pi d_{p} K_{p}\left(\frac{\partial T_{p}}{\partial r}\right)+\pi d_{c} K_{c}\left(\frac{\partial T_{a}}{\partial r}\right)=0$ (A.21)

The radial-temperature gradient in the insulation layer can be formulated as

$$
\frac{\partial T_{p}}{\partial r}=\frac{T_{a}-T_{p}}{t_{p}}
$$

and

$$
\frac{\partial T_{a}}{\partial r}=\frac{T_{g}-T_{a}}{t_{c}}
$$

Substituting (A.22) and (A.23) into (A.21) yields

$$
\frac{\partial T_{a}}{\partial L}-\lambda_{a} \frac{\partial T_{a}}{\partial t}+\beta_{a}\left(T_{p}-T_{a}\right)-\alpha_{a}\left(T_{a}-T_{g}\right)=0
$$

where

$$
\begin{array}{r}
\lambda_{a}=\frac{\rho_{a} A_{a}}{\dot{m}_{a}} \\
\beta_{a}=\frac{\pi d_{p} K_{p}}{C_{a} \dot{m}_{a} t_{p}} \\
\alpha_{a}=\frac{\pi d_{c} K_{c}}{C_{a} \dot{m}_{a} t_{c}}
\end{array}
$$

The temperatures Tp and Ta at any given depth can be solved numerically from (A.10) and (A.24).

For steady heat flow, (A.10) and (A.24) can be written as:

$$
\begin{aligned}
& \frac{\partial T_{p}}{\partial L}+\alpha_{p}\left(T_{p}-T_{a}\right)=0 \\
& \frac{\partial T_{a}}{\partial L}+\beta_{a}\left(T_{p}-T_{a}\right)-\alpha_{a}\left(T_{a}-T_{g}\right)=0
\end{aligned}
$$

where the geo-temperature can be expressed as:

$$
T_{g}=T_{g 0}+G L
$$

\section{Boundary Conditions}

The boundary conditions for solving (A.28) and (A.29) are expressed as

$$
\begin{gathered}
T_{p}=T_{p 0} \text { at } L=0 \quad \text { (A.31) } \\
T_{a}=T_{p}+\Delta T_{b} \text { at } L=L_{\max }
\end{gathered}
$$

\section{Solution}

The governing (A.28) and (A.29) subjected to the boundary conditions (A.31) and (A.32) were solved with the 
method of characteristics. The solutions take the following form:

$$
T_{p}=C_{1} A e^{r_{1} L}+C_{2} A^{e r_{2} L}+a L+\frac{A a+A B b-a(B+E)}{A B}
$$

$$
T_{a}=C_{1}\left(A+r_{1}\right) e^{r_{1} L}+C_{2}\left(A+r_{2}\right) e^{r_{2} L}+a L+\frac{A a+A B b-a E}{A B}
$$

where

$$
\begin{gathered}
C_{1}=\frac{A B(A D-a)-[A B C-A B b-A a+a(B+E)] r_{2} e^{r_{2} L_{\max }}}{A^{2} B\left(r_{1} e^{r_{1} L_{\max }}-r_{2} e^{r_{2} L_{\max }}\right)} \\
C_{2}=\frac{-A B(A D-a)+[A B C-A B b-A a+a(B+E)] r_{1} e^{r_{1} L_{\max }}}{A^{2} B\left(r_{1} e^{r_{1} L_{\max }}-r_{2} e^{r_{2} L_{\max }}\right)} \\
r_{1}=\frac{B+E-A+\sqrt{(B+E-A)^{2}+4 A B}}{2} \\
r_{2}=\frac{B+E-A-\sqrt{(B+E-A)^{2}+4 A B}}{2} \quad \text { (A.35) } \\
\text { where } A=\alpha_{p}, B=\alpha_{a}, C=T_{p 0}, \quad D=\Delta T_{b}, E=\beta_{a},
\end{gathered}
$$

